\title{
Simulation of Rollcage of an All Terrain Vehicle Attributing Differential Finite Element
}

\author{
${ }^{1} \mathrm{~S} N$ Mahathi, ${ }^{2} \mathrm{~K}$ Sreekanth Reddy \\ ${ }^{1,2}$ Automobile Engineering, MVSR Engineering College, Hyderabad, AP, India
}

\begin{abstract}
Design and simulation of the chassis of any automobile for validation against crash and consequences is the dire need of designers in the automobile industry today. This paper presents a detailed methodology in this direction and conclusions drawn might be obliging by the basic constraints and loading conditions of the real time situations. The paper describes detailed analysis and loads of the considered roll cage model. In the current study importance is given for critical points for bent sections-using two elements which has shown better results than the one with single element discretization as in the previous literatures. The design considerations include several aspects of driver ergonomics, suspension geometry, vehicle dynamics, dynamic load transfer, roll centre variations and centre of gravity positions in dynamic modes, i.e., studying the anti-dive and anti-squat concepts keenly. The following sections of the paper detail the selection criteria and factors considered in the process. The chassis is deliberately tested for its behaviour in static and impact loading, drop and heave conditions. The results are further compared with the standards and experimental values obtained in the previous literatures and annotations.
\end{abstract}

Keywords: Finite Element Model, rollcage, stress transmissibility, Elow 290, Pipe 289, impact test, factor of safety, convergence criteria.

\section{Introduction}

Unlike the conventional passenger vehicles, All Terrain Vehicles need distinctive approaches and testing during design and fabrication stages, the obvious reasons being multiplicity of loading conditions, fatigue stresses and impacts daunting the chassis at critical points. It is therefore necessary for a deeper and meticulous study of design considerations, loads and constraints. The main subsystem of an ATV is its suspension. However, the suspension geometry and its functioning confirms on the roll cage design. Nevertheless, roll cage is the element which contains all the other subsystems in it and the design of roll cage contemplates the study of all other subsystems as a whole. The roll cage also guards the driver in crash and impact situations. Hence, the design of the roll cage, in other words, its rigidity, stress transmissibility, and noise, harshness and vibration modes are to be thoroughly determined. Evidently, many researchers have been working on these lines since times, yet there has not been a definite rigid approach for validating and testing of the structures that have significantly reduced loss of lives and better security against crashes and impacts. In the previous studies and literatures, there has been FEM testing considering a single element attribution, that is, it behaves in the similar way throughout the chassis. In reality, this is not the case, although the material and its properties remain the same throughout, the stress transmissibility varies significantly at critical joints or bends. In previous studies, there has not been any method described to identify such points and analyze them differentially. This paper provides an insight on how to better choose various element type and attribute them according to their stress zones. For this purpose, several elements of possible structure have been critically analyzed and pipe element 3-node 289 is chosen for straight members and weld joints while pipe element elbow 290 is chosen for bent sections. This differential attribution of elements better synchronizes the structure with real case validation.

\section{Design methodology}

The prototype of the basic frame was designed in SOLIDWORKS workbench and corresponding model was developed in ANSYS. First iteration of loading conditions casted an unacceptable factor of safety. Further model was iterated for various real time appropriate loads and augmented in the direction of decreasing the stresses and deflections at the prone nodes. The elements were attributed for members keeping in mind the bends and welds. Since all joints when attributed Pipe 3-node 289 are considered welds at joints. For this reason bend members are attributed ELBOW 290 element type. This element type behaves as bends at the joints and shows better stress transmissibility. The combination of chosen elements is compatible and node superposing since both are 3 node elements and mesh to proper grid size. The material model is defined for Chromoly steel whose properties are given in table 1 . 
Table 1 . Mechanical properties of 4130 chromoly steel

\begin{tabular}{|c|c|}
\hline Density & $7850 \mathrm{~kg} / \mathrm{m}^{3}$ \\
\hline Ultimate tensile strength & $670 \mathrm{MPa}$ \\
\hline Permissible yield strength & $470 \mathrm{MPa}$ \\
\hline Elongation & $25.5 \%$ \\
\hline Reduction area & $60 \%$ \\
\hline Young's modulus & $205 \mathrm{GPa}$ \\
\hline Bulk's modulus & $140 \mathrm{GPa}$ \\
\hline Poisson's ratio & 0.29 \\
\hline Izod impact & $87 \mathrm{~J}$ \\
\hline Rigidity modulus & $80 \mathrm{GPa}$ \\
\hline
\end{tabular}

Modelling of Rollcage The modelling of the basic frame is started with driver's cabin. A 95 percentile male is assumed to be driving the vehicle and with sufficient spatial clearances throughout and accordingly a cabin is designed. Further, members to support subsystems like suspension, steering, brakes, transmission and engine are added. This geometry of various subsystems is deduced by considering several vehicle dynamics concepts.

Firstly, the suspension system is designed for an anti-dive and anti-squat of $30 \%$. Hence is the inclination of 5 degrees for lower wishbone bearing member and 15 degrees for upper wishbone bearing member calculated and assigned. Similarly, the width of the RRH is determined by the mounting points of rear trailing arm geometry as to provide the travel circle.

Steering rack positioning was pre-determined and accordingly space beyond foot and peripheries of the vehicle are decided upon. The lateral dimensions are determined keeping in mind the required track width and wheel base. Structural members for mounting of steering rack and columns are provided.

The rear cabin is designed aiming for a compact and safe engine mounting space and installation. The RRH is restrained from bending and rotation in the elevation plane. There is a triangulation member provided on either sides to serve this purpose.

\section{FE model development, Element Attribution and meshing.}

After the structure is determined, corresponding key points are given in ANSYS and the FE model is developed. Now the joints where there are bends and welds are distinctly identified. The straight members are attributed with 3 node Pipe 289 element, while the bending junctions are attributed Elbow element. Iterations show that the stress transmissibility through the Elbow elements is better than when a pipe joint is considered at the bend.

\section{Element Comparison Study}

Two cases have been considered to validate the attributions of the elements. First is an L-link constrained at both extremes in all degrees of freedom with Pipe 289 element attributed throughout the length. Second is a similar structure but elbow 290 element attributed at the bend joint. An inclined load is applied on the bend and the structure is analyzed for stress distribution on the length of the $\mathrm{L}$ arms. It can be observed from figure 1 (a) and (b) that although the displacement in both cases remains the same, the stress distribution and maximum stresses induced significantly vary. The second case exhibits near realistic values as experience from various experiments say that the stress distribution at the junctions is not as uniform as theoretically stated. The first case complies with the theoretical distribution functions while the later resembles a more practical distribution and transmissibility characteristics.

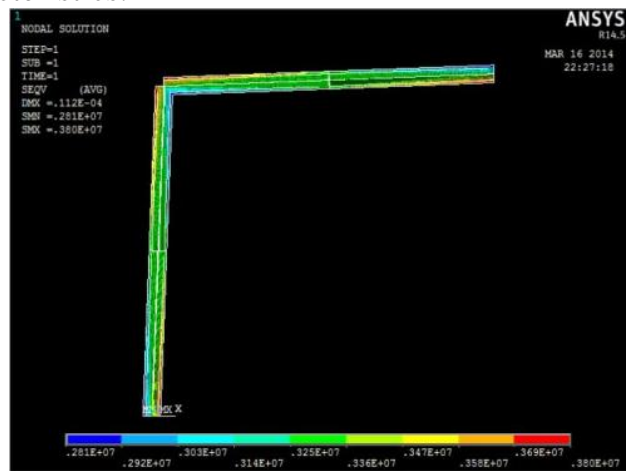

Figure 1 (a). Von Misses Stress distribution on the structure with only Pipe 289 


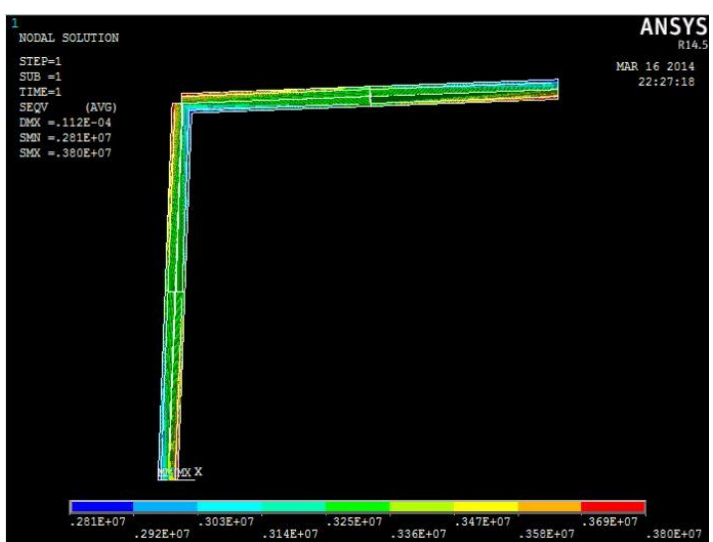

Figure 1 (b). Von Misses Stress distribution on the structure with Elbow 290 element at the junction.

\section{Static Analysis:}

The minimum requirement of any chassis is to withstand the static loads, i.e. it's self-weight and that of all its components. The system is assumed to have lumped mass concentrated at its center of mass. The complete analysis is carried out assuming a lumped mass system. The next necessary CRITERIA that needs attention is strength against crash. Firstly tested for front and side impacts, the results showed need for bracing members that support the load bearing members in order to increase the stress transmissibility and reduce deflection and corresponding stresses produced during the impact. After attributing, the mesh sizes are set and the FE model is meshed with the defined cross sections.

\section{Constraints applied on the FE model for deflection and stress.}

The movement and behavior of the rollcage when mounted with the suspension system is defined by the suspension hard points. Therefore, the frame is constrained in Uy, ROTx and ROTz for studying the displacements and stresses induced in the corresponding degrees of freedom. That is, the front double wishbone mount points of upper and lower arms on either sides comprise the front suspension hard points, while the trailing arm mount points are defined by the trailing arm geometry. After defining the displacement loads on the rollcage, the next step is to identify major loads on the vehicle and apply them on relevant node points. The major loads being, Engine and transmission loads, driver's weight and center of gravity of the rollcage tubular structure itself, it may however be noted that only sprung mass is considered for the study of the FE model.

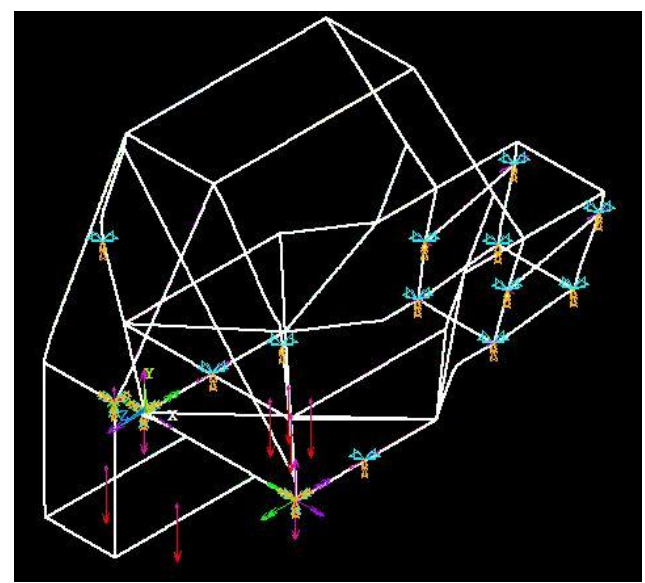

Figure 2. The figure depicts the various constraints and static loads on the rollcage.

\section{Analysis of various load conditions}

The impacts a rollcage is prone to is analyzed and checked for optimum factor of safety. Front impact, side impact, front and side roll overs, torsion, drop and heave conditions are considered. Iterations are carried out towards building a frame that fetches a satisfactory factor of safety. Another criteria was attaining convergence criteria varying the grid sizes and mesh of the FE Model. This was obtained for every test individually and tabulated. 


\section{Results}

2.

All the applied loads and corresponding displacements and maximum stresses are tabulated as in table

Table 2 Load conditions with their corresponding displacements and maximum stress

\begin{tabular}{|c|c|c|c|c|c|}
\hline S.No & Test condition & Loading & Max Stress & Deflection & FoS \\
\hline 1 & Static loading & $\begin{array}{c}\text { Self-weight of vehicle \& } \\
\text { driver }\end{array}$ & $56.9 \mathrm{MPa}$ & $0.789 \mathrm{~mm}$ & 11.88 \\
\hline 2 & Frontal Impact & $\begin{array}{c}3 \mathrm{G} \text { load on front exposed } \\
\text { corner points }\end{array}$ & $129 \mathrm{MPa}$ & 0.826 & 5.24 \\
\hline 3 & Side impact & $\begin{array}{c}2 \mathrm{G} \text { load on side impact } \\
\text { members }\end{array}$ & $156 \mathrm{MPa}$ & $3.325 \mathrm{~mm}$ & 4.33 \\
\hline 4 & Front roll over & $3 \mathrm{G}$ load on front members & $139 \mathrm{MPa}$ & $6 \mathrm{~mm}$ & 4.82 \\
\hline 5 & Side roll & $2 \mathrm{G}$ load on SIM & $145 \mathrm{Mpa}$ & $4 \mathrm{~mm}$ & 4.62 \\
\hline 6 & Torsion & $2 \mathrm{G}$ couple & $260 \mathrm{MPa}$ & $12 \mathrm{~mm}$ & 2.57 \\
\hline
\end{tabular}

\section{Conclusions}

The presented FEM is built using ELBOW 290 and Pipe 289, 3 node elements which display properties of a real bend and weld at respective nodes. The selection and attribution of the elements is clearly explained in the paper. Two Fem cases are considered, one with Elbow 290 attributed at the corner of the L linkage another with Pipe 290 throughout. The comparison of the stress distribution is also explained in spite of the equal displacement in both cases. Secondly, the Finite Element Model of the roll cage considered is constrained at the suspension hard points and analyzed for various impact conditions and torsion tests. Each result was iterated till the convergence criteria and then tabulated. Hence, the attributions and application of Elbow 290 element is demonstrated in this paper.

\section{References}

[1]. Dessault Systems SolidWorks 2013 x64 Edition user manual

[2]. ANSYS Mechanical APDL 14.5 Help

[3]. Goering, Carroll E., Marvin L Stone, David W. Smith, and Paul K. Turnquist. 2003. "Chassis mechanics". Chapter 14 in "Off-Road Vehicle Engineering Principles", 383-420. St. Joseph, Mich.: ASAE. (C) American Society of Agricultural Engineers.

[4]. Daphal, P.N and Athavale,S.M, "Full vehicle Frontal Crash and Rollover Simulation Using LS-Dyna3D and experimental Validation", The Automotive Research Association of India, Pune,India, SAE Paper no. 2001-01-0033.

[5]. Thanneru Raghu Krishna Prasad, Goutham Solasa, Nariganani SD Satyadeep, G.Suresh Babu, "Static Analysis and Optimisation of Chassis and Suspension of an All-Terrain Vehicle". International Journal of Engineering and Advanced Technology (IJEAT) ISSN: 2249 - 8958, Volume-2, Issue-5, June 2013, 